\title{
Altered tissue mineralization, increased hepatic lipid and inhibited autophagy in intrauterine growth retardation piglets
}

\author{
C. Wang ${ }^{1}$, X. C. Zheng ${ }^{1}$, F. A. Siyal ${ }^{1}$, D. Babazadeh ${ }^{2}$, T. Ayasan ${ }^{3,}$ K. Cheng, J. H. He ${ }^{1}$, W. Xu ${ }^{1}$, \\ L. L. Zhang ${ }^{1}$, X. Zhong ${ }^{1} \&$ T. Wang ${ }^{1 \#}$ \\ ${ }^{1}$ College of Animal Science and Technology, Nanjing Agricultural University, Nanjing 210095, P.R. China \\ ${ }^{2}$ Young Researchers and Elite Club, Tabriz Branch, Islamic Azad University, Tabriz, Iran \\ ${ }^{3}$ East Mediterranean Agricultural Research Institute, Adana, Turkey
}

(Received 8 May 2017; Accepted 13 September 2017; First published online 8 November 2017)

\author{
Copyright resides with the authors in terms of the Creative Commons Attribution 4.0 South African Licence. \\ See: http://creativecommons.org/licenses/by/4.0/za \\ Condition of use: The user may copy, distribute, transmit and adapt the work, but must recognise the authors and the South African \\ Journal of Animal Science.
}

\begin{abstract}
Mineral homeostasis is often disrupted in intrauterine growth retardation (IUGR) infants. Most studies focus on calcium or phosphorus metabolism of IUGR infants via determining serum mineral concentrations instead of tissues. This study was conducted to investigate the effects of IUGR on the mineralization and physiological functions of tissue in a piglet model. Six normal birth weight (NBW) and six IUGR neonatal piglets were slaughtered at 35 days. Mineral concentrations in blood and selected tissues (liver, kidney, lungs, heart, and longissimus dorsi muscle (LDM)), hepatic lipid, mRNA expressions of magnesium (Mg) metabolism, and autophagy were analysed. Results showed that IUGR pigs showed significantly lower phosphorus (P) in LDM, and lower Mg in the liver and LDM, and higher Mg in lungs than NBW pigs. There were no significant differences in concentrations of selenium (Se), calcium (Ca), copper (Cu), aluminium (Al), and lithium ( $\mathrm{Li}$ ) in selected tissues. IUGR pigs had similar mRNA expression of TRPM7 and MagT1 to NBW pigs, but significantly lower expressions of HNF1B and Mrs2 in the liver than NBW pigs. Hepatic triglyceride was significantly increased, and MAP1LC3B expression was significantly decreased in IUGR pigs compared with those of NBW pigs. These result suggested that IUGR pigs had tissue mineralization disturbance, especially for $\mathrm{Mg}$, and liver dysfunction (increased hepatic lipid and inhibited autophagy). Hepatic $\mathrm{Mg}$ deficiency might result from increased Mg efflux via reducing HNF1B expression.
\end{abstract}

Keywords: Hepatic triglyceride, magnesium metabolism, mineral homeostasis, physiological function

\# Corresponding author: tianwangnjau@163.com

\section{Introduction}

Intrauterine growth restriction (IUGR) refers to restricted growth and inhibited development of the embryo/foetus or impaired organs during pregnancy. Commonly, foetal weight less than $10^{\text {th }}$ percentile of a given population at the same gestational age is regarded as IUGR (Wu et al., 2006; Roman et al., 2013). IUGR is a severe problem in livestock. For example, in the swine industry IUGR affects more than $15 \%$ of new-born piglets (Wu et al., 2006). IUGR is associated with neonatal death and metabolic dysfunctions, such as mineral and lipid metabolic dysfunctions (Blaga et al., 2008; Li et al., 2016). Epidemiological studies indicate that IUGR exhibits side effects on postnatal growth, health and lipid metabolism for a long time, and is closely linked to hypertension, insulin resistance, and obesity in adult (Vickers, 2014).

Minerals are commonly divided into major minerals, for example $\mathrm{Ca}, \mathrm{Mg}$ and $\mathrm{P}$, and trace or microminerals for example iron ( $\mathrm{Fe})$ and $\mathrm{Cu}$. They are involved in various enzyme activities and nutrient metabolism, which have been summarized by Gharibzahedi \& Jafari (2017). Therefore, small amounts of minerals play an important role in livestock and the human body. Complicated processes and hormones, such as the parathyroid hormone, calcitriol, and sex steroids, to keep mineral homeostasis (Kovacs, 2014), regulate the mineral metabolism. However, IUGR is closely associated with disturbance in mineral homeostasis. IUGR infants fed human milk or commercial formulas show severely disturbed mineral homeostasis (Schanler et al., 1985; Schanler \& Garza, 1988; Mataloun \& Leone, 2000). Most of these studies focus on bone development and calcium or phosphorus metabolism via determining mineral concentrations in serum or bone (Prestridge et al., 1993; Li et al., 2016). However, essential minerals are abundant in tissues, in which they are critical for electrolyte balance and nutrient metabolism through being 
involved in the activities of enzymes (Moltu et al., 2013; Gupta et al., 2014; Gharibzahedi \& Jafari, 2017). For example, Mg-deficient foetal livers of IUGR mice are accompanied by low monounsaturated fatty acids (MUFAs), high polyunsaturated fatty acids (PUFAs), and low desaturase and elongase mRNA expression (Gupta et al., 2014). Therefore, it seems necessary to determine the mineral contents and their metabolism in tissues. However, few studies have investigated the effects of IUGR on tissue mineralization.

It was hypothesized that IUGR might impair tissue mineralization and affect the physiological functions of tissues with mineral disturbance. To test this hypothesis, a pig model of IUGR was used, because pigs are the optimal model for human (Darragh \& Moughan, 1995; Kues \& Niemann, 2004; Pearce et al., 2007). After the liver mineral disturbance (especially for $\mathrm{Mg}$ ) was found, $\mathrm{Mg}$ metabolism-related gene expressions, hepatic lipid, and autophagy were analysed. This study could provide additional information for neonatal nutrition research, especially for the IUGR infants.

\section{Materials and methods}

This study was approved by the Institutional Animal Care and Use Committee of Nanjing Agricultural University, China. At the time of parturition (114 days gestation), six normal birth weight (NBW) (1.54 \pm $0.01 \mathrm{~kg})$ and six IUGR $(0.93 \pm 0.02 \mathrm{~kg})$ Duroc $\times$ Landrace $\times$ Large White piglets were chosen from six similar birth order (third and fourth) sows with the same litter size (each litter 10 piglets). Each IUGR piglet and one same sex sibling of NBW piglets were chosen, as discussed in previous reports (Xu et al., 1994; Wu et al., 2006). Piglets stayed with their own mothers until 14 days. After weaning, piglets were fed individually with water and feed ad libitum. The feed was formulated to meet or exceed the nutritional requirements of NRC (1998), as shown in Table 1.

Table 1 Composition of diet (as-fed basis) for weaning piglets

\begin{tabular}{|c|c|c|c|}
\hline Ingredients $(\mathrm{g} / 100 \mathrm{~g})$ & & Nutrient composition (\%) & \\
\hline Corn & 40.00 & Crude protein & 20.20 \\
\hline Rice, broken & 15.00 & Digestible energy (Mcal/kg) & 3.40 \\
\hline Soybean meal, fermented & 10.00 & Total calcium & 0.85 \\
\hline Soybean meal, de-hulled & 6.00 & Total phosphorus & 0.70 \\
\hline Spray dried animal plasma & 5.00 & Digestible lysine & 1.45 \\
\hline Whey powder & 7.00 & Digestible methionine +cystine & 0.79 \\
\hline Fish meal & 4.00 & Digestible threonine & 0.81 \\
\hline Sugar & 4.50 & Digestible tryptophan & 0.23 \\
\hline Glucose & 3.00 & Digestible isoleucine & 0.74 \\
\hline Soybean oil & 1.50 & Digestible leucine & 1.45 \\
\hline L-Lysine-HCl & 0.30 & Digestible valine & 0.89 \\
\hline L-Methionine & 0.15 & & \\
\hline L-Threonine & 0.20 & & \\
\hline L-Tryptophan & 0.05 & & \\
\hline L-Isoleucine & 0.05 & & \\
\hline L-Valine & 0.05 & & \\
\hline Salt & 0.30 & & \\
\hline Limestone & 1.10 & & \\
\hline Dicalcium phosphate & 0.80 & & \\
\hline Vitamin mixture ${ }^{a}$ & 0.20 & & \\
\hline Mineral mixture ${ }^{b}$ & 0.80 & & \\
\hline Total & 100.00 & & \\
\hline
\end{tabular}

a Vitamin mixture supplied per kg complete diet: vitamin $A, 15,000$ IU; vitamin $\mathrm{D}_{3}, 3,000 \mathrm{IU}$; vitamin $\mathrm{E}, 150 \mathrm{mg}$; vitamin $\mathrm{K}_{3}$, $3.00 \mathrm{mg}$; vitamin $B_{1}, 3.00 \mathrm{mg}$; vitamin $B_{2}, 6.00 \mathrm{mg}$; vitamin $B_{6}, 5.00 \mathrm{mg}$; vitamin $B_{12}, 0.03 \mathrm{mg}$; niacin, $45.00 \mathrm{mg}$; vitamin C, $250 \mathrm{mg}$; calcium pantothenate, $9.00 \mathrm{mg}$; folic acid, $1.00 \mathrm{mg}$; biotin, $0.30 \mathrm{mg}$; choline chloride, $500 \mathrm{mg}$. ${ }^{\mathrm{b}} \mathrm{Mineral}$ mixture supplied per kg complete diet: Fe, 170 mg; Cu, 150 mg; I, 0.90 mg; Se,0.20 mg; Zn, 150 mg; Mg, 68 mg; Mn, 80 $\mathrm{mg}$; Co, $0.30 \mathrm{mg}$ 
At 0,14 , and 35 days, bodyweight and average daily feed intake (ADFI) (14-35 days) were recorded. $A D G$ and feed/gain ratio ( $F: G$ ) were calculated. At the end of this experiment (35 days), whole blood was collected with heparinized tubes two hours after their last meal. All pigs were slaughtered via electrical stunning. Samples to determine mineral concentrations and mRNA expression were collected as described by Wang et al. (2016). Briefly, lungs, heart, kidney, liver, and longissimus dorsi muscle (LDM) were collected and stored at $-20{ }^{\circ} \mathrm{C}$ to determine mineral concentration. Liver samples were frozen quickly and stored at $80^{\circ} \mathrm{C}$ to determine mRNA expression and lipid metabolism.

The mineral concentrations ( $\mathrm{Se}, \mathrm{P}, \mathrm{Fe}$, chromium ( $\mathrm{Cr}$ ), $\mathrm{Mg}, \mathrm{Ca}, \mathrm{Cu}, \mathrm{Al}$, and $\mathrm{Li}$ ) were determined as described by Demirbaş (1999). Briefly, tissues (2-3 g) and blood (3-3.5 ml) were digested using a mixture of HNO3 : $\mathrm{HClO} 4(\mathrm{v} / \mathrm{v}=4: 1)$. After cooling, the digest was dissolved with demineralized water to $25 \mathrm{ml}$. Subsequently, it was diluted to the optimal concentrations. Mineral concentrations were determined by inductively coupled plasma mass spectrometry (ICP-MS) (Agilent, USA).

Total RNA of the liver was extracted with Trizol reagents, and reverse transcription was conducted as described by Dong et al. (2014). Briefly, after the RNA quality had been verified by a Thermo Fisher Scientific Nanodrop 2000 spectrophotometer (ratios of absorption including 260/280 nm and 260/230 nm between 1.90 and 2.05) and by agarose gel electrophoresis, $2 \mu \mathrm{g}$ RNA were incubated at $72{ }^{\circ} \mathrm{C}$ with random primer (Promega, Belgium) for $5 \mathrm{~min}$, then incubated for 1 hour with reverse transcription mixture (Takara, Dalian, China). Finally, the reverse transcription was inactivated at $90{ }^{\circ} \mathrm{C}$ for $10 \mathrm{~min}$.

In this study, Mg metabolism-related gene expressions of TRPM7, MagT1, Mrs2, HNF1B, and autophagy-related gene expressions of MAP1LC3A, MAP1LC3B and Atg5 in the liver were determined. The related gene primers are listed in Table 2 and were synthesized in Invitrogen (Shanghai) Biotech Co. Ltd. (Shanghai, China). GAPDH was used as a housekeeping gene. Reverse transcription polymerase chain reaction (RT-PCR) assays were conducted with the ABI 7300 RT-PCR system with a SYBR Premix Ex TaqTM Kit (TakaRa, Dalian, China) according to the manufacturer's instructions. The mRNA expressions were examined with $\mathrm{ABI}$ software and calculated with the $2-\triangle \triangle \mathrm{Ct}$, as previous reports (Livak \& Schmittgen, 2001).

Table 2 Primer sequences used in quantitative real-time polymerase chain reaction assays

\begin{tabular}{|c|c|c|c|c|}
\hline Genes & Accession No. & Primers & Sequences(5'--3') & bp \\
\hline \multirow{2}{*}{ GAPDH } & \multirow{2}{*}{ NM_001206359.1 } & Forward & CATTGCCCTCAACGACCACT & \multirow{2}{*}{84} \\
\hline & & Reverse & ATGAGGTCCACCACCCTGTT & \\
\hline \multirow{2}{*}{ TRPM7 } & \multirow{2}{*}{ XM_003121515.2 } & Forward & CCCGATAGATGGCTACAGGC & \multirow{2}{*}{85} \\
\hline & & Reverse & CTGGGACATTCTCCTCACGG & \\
\hline \multirow{2}{*}{ MagT1 } & \multirow{2}{*}{ XM_003135205.4 } & Forward & GCCTGTTTTTGTTACGCCCC & \multirow{2}{*}{77} \\
\hline & & Reverse & TGGCCTGAGGCAAGTACAAG & \\
\hline \multirow{2}{*}{ HNF1B } & \multirow{2}{*}{ NM_213956.1 } & Forward & CGACAAACCACGGAAGAGGA & \multirow{2}{*}{157} \\
\hline & & Reverse & GGTGGCTGATGTTTACAGTGTG & \\
\hline \multirow{2}{*}{ Mrs2 } & \multirow{2}{*}{ XM_001928036 } & Forward & GGCGTTTGCTGTCATTCCTC & \multirow{2}{*}{126} \\
\hline & & Reverse & CATCCGGTCTGAAGCTGTGT & \\
\hline \multirow{2}{*}{ MAP1LC3A } & \multirow{2}{*}{ NM_001170827.1 } & Forward & GTCTACGCCTCCCAGGAAAC & \multirow{2}{*}{127} \\
\hline & & Reverse & CAGGGGCAGAGACAGCTTAG & \\
\hline \multirow{2}{*}{ MAP1LC3B } & \multirow{2}{*}{ NM_001190290.1 } & Forward & CCACGTCCATCCCAGTGTAT & \multirow{2}{*}{200} \\
\hline & & Reverse & GGTTCCTGTTGAGCAGTGGT & \\
\hline \multirow{2}{*}{ Atg5 } & \multirow{2}{*}{ NM_001037152 } & Forward & GACCTTCTGCACTGTCCATCA & \multirow{2}{*}{181} \\
\hline & & Reverse & TCCGGTTGATGGTCCAAAACT & \\
\hline
\end{tabular}

Hepatic lipid content was analysed as described by Ahn et al. (2008). Briefly, portions of liver samples from each pig were weighed and homogenized in Tris- $\mathrm{HCl}$ solution with a glass Dounce homogenizer on ice. The $\mathrm{TG}$ and $\mathrm{CHO}$ contents in the liver were determined with commercial kits (Nanjing Jiancheng Bioengineering Institute, Nanjing, China). 
All the data were processed with the student t-test of the SPSS statistical package (Version 20.0, SPSS Inc., Chicago, IL) as described by Dong et al. (2014). Results were shown as mean \pm SE. P value below 0.05 was regarded as significant.

\section{Results}

In this study, the bodyweights of IUGR pigs were lower than NBW pigs at 0,14 and 35 days $(P<$ 0.01). Compared with the NBW pigs, IUGR pigs exhibited significantly lower ADGs (0-14 days and 14-35 days), less ADFI (14-35 days), and higher F: G (14-35 days), as shown in Table 3.

Table 3 Effects of intrauterine growth retardation on growth performance in pigs

\begin{tabular}{lcc}
\hline Items & NBW & IUGR \\
\hline Bodyweight $(\mathrm{kg})$ & & $0.93 \pm 0.02^{\mathrm{B}}$ \\
0 days & $1.54 \pm 0.01^{\mathrm{A}}$ & $3.45 \pm 0.05^{\mathrm{B}}$ \\
14 days & $5.38 \pm 0.06^{\mathrm{A}}$ & $6.03 \pm 0.23^{\mathrm{B}}$ \\
35 days & $9.95 \pm 0.40^{\mathrm{A}}$ & \\
ADG (kg/d) & & $0.18 \pm 0.01^{\mathrm{B}}$ \\
0-14 days & $0.27 \pm 0.01^{\mathrm{A}}$ & $0.12 \pm 0.01^{\mathrm{B}}$ \\
14-35 days & $0.20 \pm 0.02^{\mathrm{A}}$ & $0.22 \pm 0.01^{\mathrm{b}}$ \\
ADFI (kg/d, 14-35d) & $0.28 \pm 0.02^{\mathrm{a}}$ & $1.82 \pm 0.11^{\mathrm{B}}$
\end{tabular}

Data were expressed as means \pm SE $(n=6)$; a-b $(P<0.05)$ or A-B $(P<0.01)$ with different superscripts between values for NBW and IUGR pigs mean significant differences

NBW: normal birth weight; IUGR: intrauterine growth retardation; ADG: average daily gain; ADFI: average daily feed intake; $F$ : G: feed/gain ratio

The effects of IUGR on the mineral concentrations of the liver, LDM, heart, lungs and kidney are shown in Table 4. There were no significant differences in the $\mathrm{Se}, \mathrm{Ca}, \mathrm{Cu}, \mathrm{Al}$, and $\mathrm{Li}$ levels of these tissues between IUGR and NBW pigs $(P>0.05)$. However, IUGR pigs had lower $\mathrm{Cr}(P<0.05)$ and $\mathrm{Mg}(P<0.01)$ in the liver and LDM, and higher $\mathrm{Mg}$ in the lungs $(P<0.01)$ than NBW pigs. Lower $\mathrm{P}$ concentration in the LDM $(P<0.05)$ and $\mathrm{Fe}$ concentration in the lungs $(P<0.05)$ were found in IUGR pigs than in those of NBW pigs. 
Table 4 Effect of intrauterine growth retardation on mineral concentrations of selected organs in pigs

\begin{tabular}{|c|c|c|c|c|c|c|c|c|c|c|}
\hline \multirow{2}{*}{ Items } & \multicolumn{2}{|c|}{ Liver } & \multicolumn{2}{|c|}{ LDM } & \multicolumn{2}{|c|}{ Heart } & \multicolumn{2}{|c|}{ Lung } & \multicolumn{2}{|c|}{ Kidney } \\
\hline & NBW & IUGR & NBW & IUGR & NBW & IUGR & NBW & IUGR & NBW & IUGR \\
\hline $\mathrm{Se}^{1}$ & $0.023 \pm 0.002$ & $0.025 \pm 0.002$ & $0.018 \pm 0.007$ & $0.009 \pm 0.002$ & $0.017 \pm 0.002$ & $0.018 \pm 0.002$ & $0.019 \pm 0.003$ & $0.023 \pm 0.003$ & $0.063 \pm 0.003$ & $0.069 \pm 0.007$ \\
\hline$P^{2}$ & $357.02 \pm 5.68$ & $367.35 \pm 6.79$ & $350.77 \pm 5.38 a$ & $324.48 \pm 7.20 b$ & $245.19 \pm 4.56$ & $244.72 \pm 4.84$ & $294.31 \pm 17.06$ & $321.81 \pm 8.76$ & $326.47 \pm 7.88$ & $327.55 \pm 7.71$ \\
\hline $\mathrm{Fe}^{1}$ & $25.12 \pm 3.12$ & $50.07 \pm 7.99$ & $48.88 \pm 2.93$ & $43.57 \pm 3.32$ & $11.41 \pm 0.51$ & $9.79 \pm 0.70$ & $91.81 \pm 5.51$ & $21.93 \pm 8.76^{\star *}$ & $90.74 \pm 7.78$ & $102.84 \pm 18.78$ \\
\hline $\mathrm{Cr}^{1}$ & $24.50 \pm 1.05$ & $21.52 \pm 0.79^{*}$ & $15.83 \pm 1.45$ & $11.96 \pm 1.12$ & $51.05 \pm 4.60$ & $43.26 \pm 0.71$ & $26.65 \pm 1.30$ & $31.49 \pm 2.65$ & $25.18 \pm 2.72$ & $20.71 \pm 0.84$ \\
\hline $\mathrm{Mg}^{2}$ & $15.63 \pm 0.30 \mathrm{~A}$ & $14.47 \pm 0.25 B$ & $18.55 \pm 0.50 \mathrm{~A}$ & $16.45 \pm 0.34 \mathrm{~B}$ & $21.49 \pm 0.41$ & $22.12 \pm 0.43$ & $14.16 \pm 0.63 \mathrm{~A}$ & $16.70 \pm 0.56 \mathrm{~B}$ & $16.10 \pm 0.34$ & $16.35 \pm 0.41$ \\
\hline $\mathrm{Ca}^{2}$ & $3.50 \pm 0.29$ & $3.65 \pm 0.14$ & $2.62 \pm 0.14$ & $2.61 \pm 0.16$ & $4.29 \pm 0.12$ & $4.88 \pm 0.29$ & $7.12 \pm 0.42$ & $7.58 \pm 0.29$ & $5.61 \pm 0.29$ & $5.54 \pm 0.19$ \\
\hline $\mathrm{Cu}^{2}$ & $1.25 \pm 0.11$ & $1.40 \pm 0.24$ & $0.063 \pm 0.001$ & $0.065 \pm 0.003$ & $0.319 \pm 0.012$ & $0.315 \pm 0.017$ & $0.078 \pm 0.001$ & $0.088 \pm 0.001$ & $5.76 \pm 0.28$ & $5.99 \pm 0.93$ \\
\hline $\mathrm{Al}^{1}$ & $208.20 \pm 30.29$ & $172.00 \pm 9.03$ & $304.22 \pm 47.73$ & $349.75 \pm 47.17$ & $173.37 \pm 79.95$ & $144.55 \pm 14.24$ & $219.29 \pm 27.16$ & $213.46 \pm 31.04$ & $204.22 \pm 10.60$ & $230.16 \pm 33.15$ \\
\hline $\mathrm{Li}^{1}$ & $4.22 \pm 0.06$ & $4.39 \pm 0.17$ & $0.63 \pm 0.06$ & $0.65 \pm 0.07$ & $3.45 \pm 0.15$ & $3.74 \pm 0.09$ & $1.68 \pm 0.14$ & $1.84 \pm 0.13$ & $1.74 \pm 0.10$ & $2.04 \pm 0.01$ \\
\hline
\end{tabular}

Data were expressed as means \pm SE $(n=6)$; a-b $(P<0.05)$ or A-B $(P<0.01)$ with different superscripts between values for NBW and IUGR pigs means significant differences; $1 \mu \mathrm{g} / 100 \mathrm{~g}$ wet tissue weight; $2 \mathrm{mg} / 100 \mathrm{~g}$ wet tissue weight

NBW: normal birth weight; IUGR: intrauterine growth retardation; LDM: longissimus dorsi muscle 
There were no significant differences in concentrations of Se, $\mathrm{P}, \mathrm{Fe}, \mathrm{Mg}, \mathrm{Ca}, \mathrm{Cu}, \mathrm{Al}$ and $\mathrm{Li}$ in blood between IUGR and NBW pigs $(P>0.05)$ as stated in Table 5. However, IUGR pigs had lower blood $\mathrm{Cr}$ level compared with NBW pigs $(P<0.05)$.

Table 5 Effects of intrauterine growth retardation on the mineral concentration of blood in pigs

\begin{tabular}{lcc}
\hline Items & NBW & IUGR \\
\hline $\mathrm{Se}(\mu \mathrm{g} / \mathrm{L})$ & $0.06 \pm 0.02$ & $0.06 \pm 0.02$ \\
$\mathrm{P}(\mathrm{mg} / \mathrm{L})$ & $606.89 \pm 14.53$ & $600.18 \pm 44.56$ \\
$\mathrm{Fe}(\mu \mathrm{g} / \mathrm{L})$ & $549.32 \pm 60.29$ & $696.29 \pm 47.70$ \\
$\mathrm{Cr}(\mu \mathrm{g} / \mathrm{L})$ & $458.22 \pm 35.62^{\mathrm{a}}$ & $328.11 \pm 41.41^{\mathrm{b}}$ \\
$\mathrm{Mg}(\mathrm{mg} / \mathrm{L})$ & $61.84 \pm 1.23$ & $61.37 \pm 3.09$ \\
$\mathrm{Ca}(\mathrm{mg} / \mathrm{L})$ & $67.97 \pm 1.25$ & $69.26 \pm 1.98$ \\
$\mathrm{Cu}(\mathrm{mg} / \mathrm{L})$ & $1.54 \pm 0.19$ & $1.25 \pm 0.10$ \\
$\mathrm{Al}(\mu \mathrm{g} / \mathrm{L})$ & $499.23 \pm 21.43$ & $483.71 \pm 31.00$ \\
$\mathrm{Li}(\mu \mathrm{g} / \mathrm{L})$ & $36.15 \pm 0.67$ & $34.95 \pm 1.67$
\end{tabular}

Data are expressed as means \pm SE $(n=6)$

${ }^{\mathrm{a}-\mathrm{b}}(P<0.05)$ different superscripts between values for NBW and IUGR pigs mean significant differences

NBW: normal birth weight; IUGR: intrauterine growth retardation

There were no differences in relative mRNA levels of TRPM7 and MagT1 between the two groups $(P>0.05)$ (Figure 1). However, the relative mRNA levels of Mrs2 and HNF1B were significantly reduced in IUGR pigs compared with NBW pigs $(P<0.05)$.
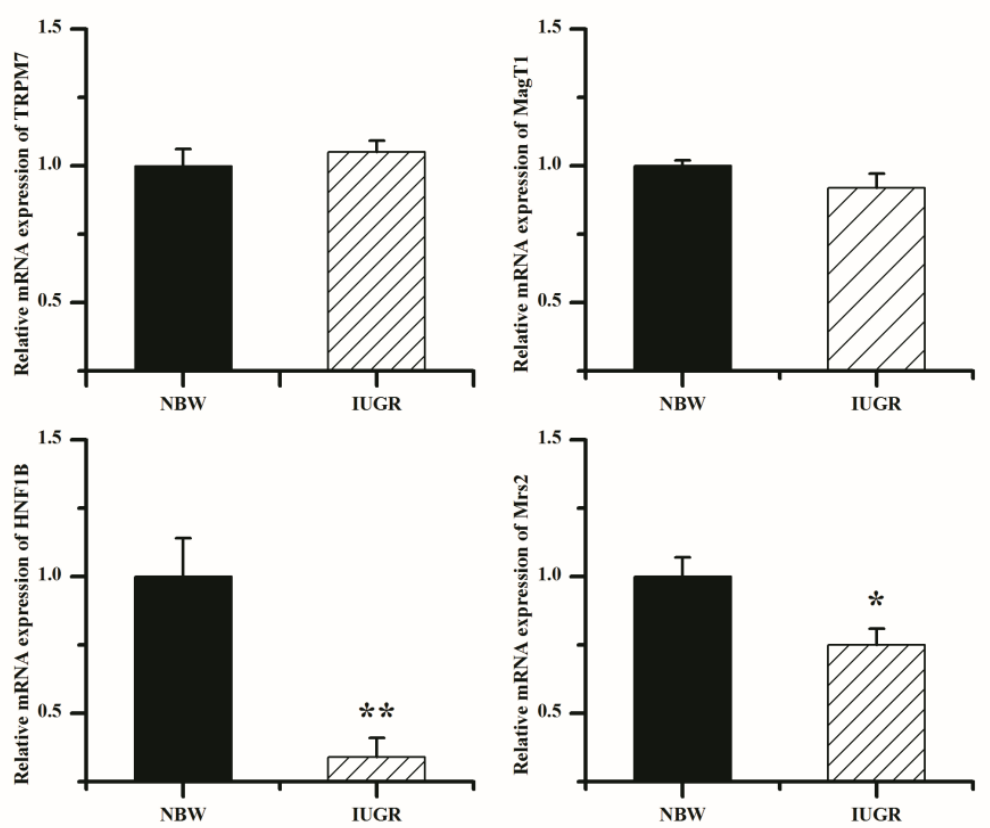

Figure 1 mRNA abundance of magnesium metabolism-related genes in liver of intrauterine growth retardation and normal birth weight pigs

Data expressed relative to the housekeeping gene GAPDH, normalized to the NBW group, and represent means \pm SE (n $=6) .{ }^{*} P<0.05,{ }^{* *} P<0.01$

NBW: normal birth weight; IUGR: intrauterine growth retardation 
IUGR pigs had a significantly higher hepatic TG level relative to the NBW pigs $(P=0.01)$, while hepatic $\mathrm{CHO}$ levels in IUGR and NBW pigs were similar $(P>0.05)$, as shown in Figure 2 . The relative mRNA expressions of MAP1LC3B and MAP1LC3B : MAP1LC3A ratio were increased in IUGR pigs compared with NBW pigs $(P<0.05)$, as shown in Figure 3. There were no significant differences in relative mRNA expressions of MAP1LC3A and ATG5 in the liver between IUGR and NBW pigs $(P>0.05)$.
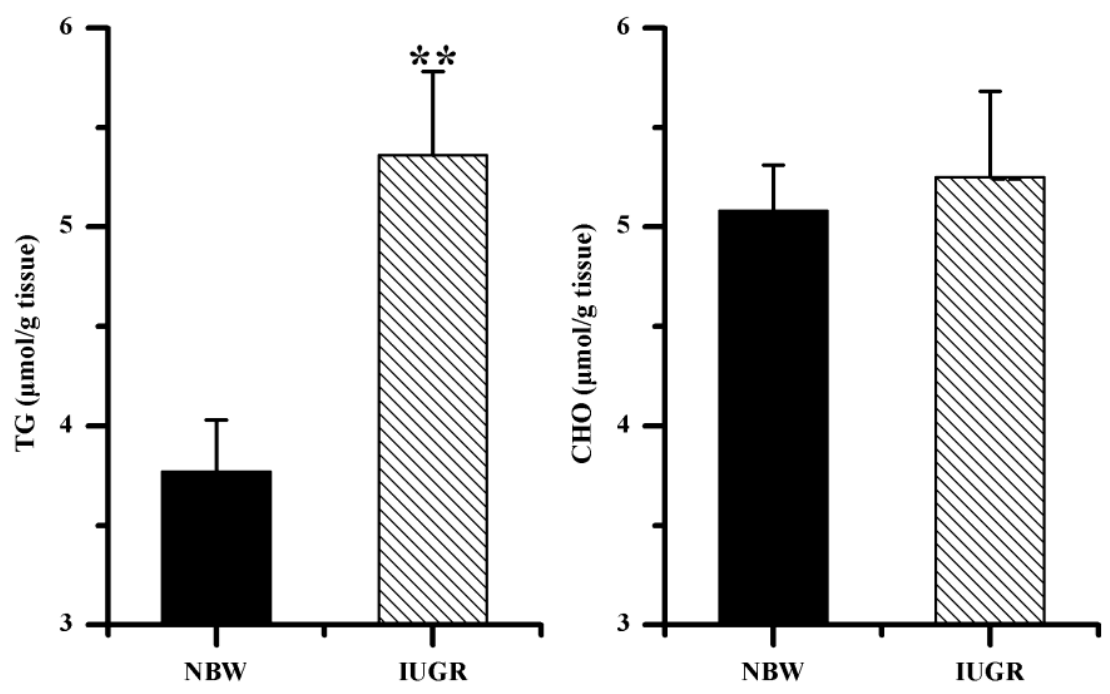

Figure 2 Hepatic lipid in intrauterine growth retardation and normal birth weight pigs Data represent means \pm SE $(n=6) ;{ }^{* *} P<0.01$ NBW: normal birth weight; IUGR: intrauterine growth retardation; TG: triglyceride; CHO: cholesterol
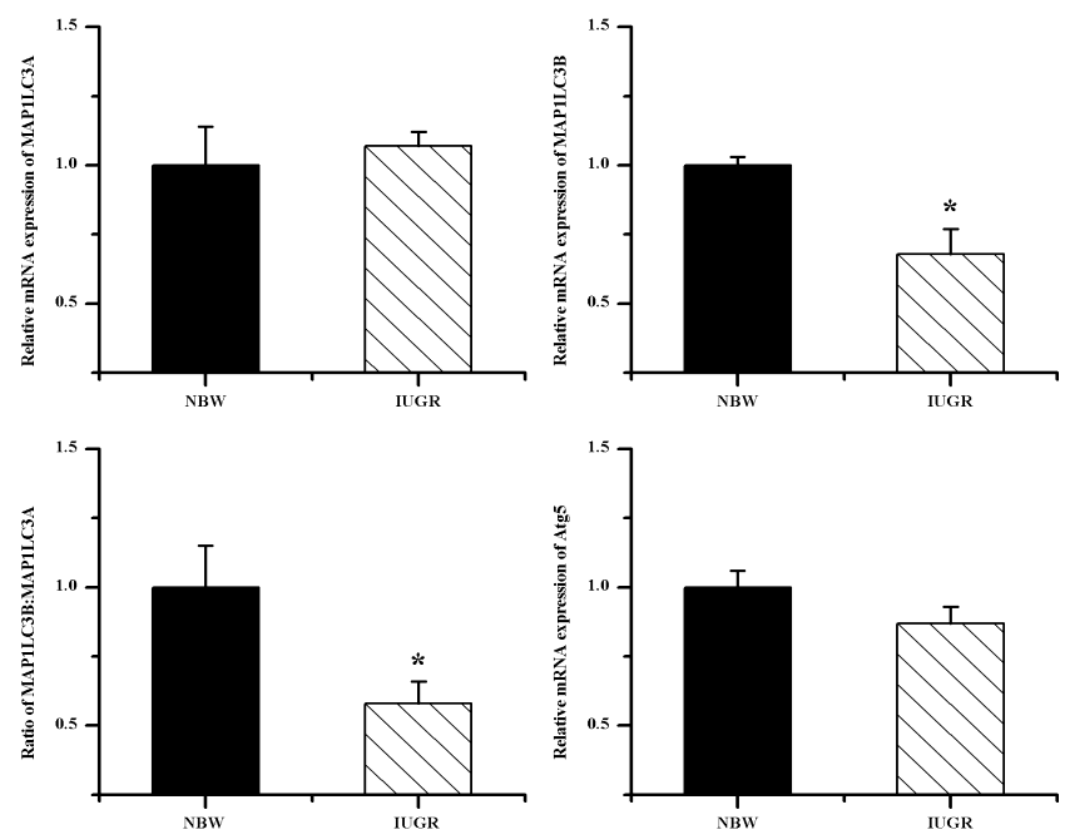

Figure 3 mRNA abundance of autophagy related genes in liver of intrauterine growth retardation and normal birth weight pigs

Data expressed relative to the housekeeping gene GAPDH, normalized to the NBW group and represent means \pm SE ( $\mathrm{n}$ $=6) ;{ }^{*} P<0.05$

NBW: normal birth weight; IUGR: intrauterine growth retardation 


\section{Discussion}

Most essential minerals, such as Mg, as components of enzymes, are involved in major metabolic pathways in tissues. IUGR neonates are more susceptible to serum mineral disturbance and need long-term mineral supplement as they were fed on their own mother's milk (Raupp et al., 1990; Blaga et al., 2008). It was further hypothesized that IUGR might impair tissue mineralization and physiological functions of tissues.

The results of this study indicated that IUGR pigs had decreased bodyweight, lower ADGs, reduced ADFI (14-35 days), and higher $F$ : G (14-35 days) than NBW pigs. These findings coincide with those of previous studies (Poore \& Fowden, 2004; Attig et al., 2008; Zhang et al., 2014; Li et al., 2015; Zhang et al., 2016).

Many factors can lead to the lower ADGs of IUGR and high nutrient density is encouraged for IUGR infants to alter the long-term adverse effects on restricted growth, such as high protein and energy (Desai et al., 2005; Desai et al., 2007; Senterre \& Rigo, 2011; Senterre \& Rigo, 2012). However, the safety of early nutrient enhancement of IUGR needs to be further evaluated, as it may cause adult obesity (Desai et al., 2005; Desai et al., 2007) and more severe mineral disturbance (Moltu et al., 2013).

It was reported that IUGR infants had reduced serum $\mathrm{P}$ concentration, and showed hypophosphatemia (Moltu et al., 2013) and that bone mineralization was affected (Abrams et al., 1988; Li et al., 2016). In the present study, IUGR pigs had lower P level in the LDM than NBW pigs. However, there was no difference in blood P content between IUGR and NBW pigs. The time of collecting blood may partially account for the lack of change in blood P level, as the blood samples were collected two hours after the last meal to evaluate the absorption of minerals.

Furthermore, the current results showed that IUGR and NBW pigs had similar Mg concentrations in the blood, heart, and kidneys. Moltu et al. (2013) reported that enhanced feeding in IUGR infants might cause electrolyte disturbances without affecting the serum Mg level. Dauncey et al. (1977) suggested that breast milk supplies enough Mg for IUGR infants by determining the serum Mg. However, IUGR pigs showed lower Mg concentrations in the liver and LDM, and higher Mg concentrations in the lungs than NBW pigs in the present study, suggesting that Mg metabolism was disturbed.

Since the liver is an important organ that distributes $\mathrm{Mg}$ in tissues, the expression of $\mathrm{Mg}$ metabolismrelated genes in the liver was further determined. The results indicated that IUGR and NBW pigs had similar relative mRNA expression of TRPM7 and MagT1. TRPM7 is ubiquitous and emphasizes the role in control of Mg influx in individual cells (Romani, 2011). MagT1 is highly expressed in the liver and appears to be highly specific for Mg ion influx (Sontia \& Touyz, 2007; Romani, 2011). No differences in relative mRNA expression of TRPM7 and MagT1 suggested that IUGR may not affect the influx of Mg in the liver. However, the expression of HNF1B and Mrs2 were decreased in the liver of IUGR pigs. The HNF1B was first identified in the liver (Cereghini et al., 1988), could bind to the FXYD2 gene, encode the $\mathrm{Y}$-subunit of the Na/K-ATPase, and is an important molecular player in the renal $\mathrm{Mg}$ reabsorption (Ferre et al., 2011). The lack of $\mathrm{Mg}$ is often associated with HNF1B deficiency (Adalat et al., 2009; Heidet et al., 2010), while dietary Mg restriction could enhance HNF1B expression (Van Angelen et al., 2013). Reduced relative mRNA expression of HNF1B may increase the efflux of $\mathrm{Mg}$ and decrease the $\mathrm{Mg}$ content in the liver of IUGR pigs. The Mrs2 plays an essential role in regulating mitochondrial $\mathrm{Mg}$ homeostasis (Romani, 2011). A deficiency in Mrs2 leads to a decrease in total mitochondrial $\mathrm{Mg}$ level, a decrease in matrix-free $\mathrm{Mg}$ ion concentration, and the dysfunction of mitochondria respiration (Martin et al., 2003). In contrast, over-expression of Mrs2 markedly increased Mg content in mitochondria (Martin et al., 2003). Decreased expression of Mrs2 indicated Mg influx in mitochondria was inhibited and the dysfunction of liver mitochondria of IUGR pigs (Zhang et al., 2016; Zhang et al., 2017), although the mitochondria function was not determined here.

$\mathrm{Mg}$ is one of the most abundant intracellular cations and is involved in over 300 enzyme activities, which play important roles in many functions of tissues (Swaminathan, 2003; Das, 2016). Recently, Mg deficiency was linked closely with incidence of IUGR, growth performance and hepatic lipid metabolic disorder in the rat model (Roman et al., 2013; Roman et al., 2015). Since the hepatic Mg deficiency of IUGR pigs was proved in the present study, the authors determined the hepatic lipid content and autophagy, which is critical in hepatic lipid metabolism (Liu \& Czaja, 2013). In the present study, hepatic TG was increased in IUGR pigs, which was partly in agreement with previous reports (Gupta et al., 2014; He et al., 2015). The mRNA of MAP1LC3B was synthesized before the MAP1LC3 protein, which is a common indicator of autophagy. Determining the MAP1LC3B mRNA expression is regarded as a convenient method to monitor the autophagosome formation (Tsuyuki et al., 2014). In this study, the relative mRNA expressions of MAP1LC3B and MAP1LC3B : MAP1LC3A ratios were decreased, suggesting that the autophagy was inhibited in the liver of IUGR pigs. Inhibited hepatic autophagy could reduce lipolysis, lead to lipid droplet accumulation and elevate hepatic TG content (Singh et al., 2009a; Singh et al., 2009b; Liu \& Czaja, 2013). These results suggested that reduced hepatic autophagy might be related to increased hepatic lipids. However, in future, more in-depth studies are required to investigate the possible pathways behind reduced 
hepatic autophagy. Controlling hepatic autophagy may be a novel way to regulate hepatic lipids in IUGR pigs.

\section{Conclusions}

In summary, the current results revealed that IUGR still showed reduced growth performance at the age of 35 days, with some disturbances in tissue mineralization, especially for Mg. The possible mechanism for hepatic Mg deficiency might be attributed to the increased Mg efflux through reducing HNF1B expression. Hepatic Mg deficiency might be related to increased hepatic autophagy and lipid contents. This study will help researchers to uncover the critical areas of tissue mineral disturbances and their related biological functions in IUGR pigs that have not been explored before. However, further studies are required to investigate possible ways to regulate hepatic $\mathrm{Mg}$ metabolism and autophagy in IUGR nursery pigs.

\section{Acknowledgements}

This study was supported by A Project funded by the Priority Academic Program Development of Jiangsu Higher Education Institutions II (PAPD II) and by Open Fund Project in Jiangsu Provincial Key Laboratory of Gastrointestinal Nutrition and Animal Health (Grant No. 2015js02).

\section{Authors' contributions}

CW and TW conceived and designed the experiments CW, XCZ, FAS, KC, WX and JTH performed the experiments. CW analysed the data. CW and LLZ contributed reagents, materials and analysis tools. CW and $X Z$ wrote the paper. DB and TA edited it.

\section{Conflict of interest declaration}

The authors declare that they have no conflict of interest.

\section{References}

Abrams, S.A., Schanler, R.J. \& Garza, C., 1988. Bone mineralization in former very low birth weight infants fed either human milk or commercial formula. J. Pediatr. 112, 956-960.

Adalat, S., Woolf, A.S., Johnstone, K.A., Wirsing, A. Harries, L.W., Long, D.A., Hennekam, R.C., Ledermann, S.E., Rees, L., van't Hoff, W., Marks, S.D., Trompeter, R.S., Tullus, K., Winyard, P.J., Cansick, J., Mushtaq, I., Dhillon, H.K., Bingham, C., Edghill, E.L., Shroff, R., Stanescu, H., Ryffel, G.U., Ellard, S. \& Bockenhauer, D., 2009. Hnf1b mutations associate with hypomagnesemia and renal magnesium wasting. J. Ameri. Societ. Nephrol. 20, 11231131.

Ahn, J., Cho, I., Kim, S., Kwon, D. \& Ha, T., 2008. Dietary resveratrol alters lipid metabolism-related gene expression of mice on an atherogenic diet. J. Hepatol. 49, 1019-1028.

Attig, L., Djiane, J., Gertler, A., Rampin, O., Larcher, T., Boukthir, S., Anton, P.M., Madec, J.Y., Gourdou, I. \& AbdennebiNajar, L., 2008. Study of hypothalamic leptin receptor expression in low-birth-weight piglets and effects of leptin supplementation on neonatal growth and development. Ameri. J. Physiol. Endocrinol. Metabol. 295, E1117-1125.

Blaga, L., Zaharie, G., Mihu, D. \& Ciortea, R., 2008. Mineral disturbance in low birth weight infant. Early Hum. Dev. 84, S126-127.

Cereghini, S., Blumenfeld, M. \& Yaniv, M., 1988. A liver-specific factor essential for albumin transcription differs between differentiated and dedifferentiated rat hepatoma-cells. Gene. Dev. 2, 957-974.

Darragh, A.J. \& Moughan, P.J., 1995. The three-week-old piglet as a model animal for studying protein digestion in human infants. J. Pediatr. Gastrl. Nutr. 21, 387-393.

Das, U.N., 2016. Beneficial actions of magnesium in metabolic syndrome: Why and how? Nutrion. 32, 1308-1310.

Dauncey, M.J., Shaw J.C. \& Urman, J., 1977. The absorption and retention of magnesium, zinc, and copper by low birth weight infants fed pasteurized human breast milk. Pediatr. Res. 11, 1033-1039.

Demirbaş, A., 1999. Proximate and heavy metal composition in chicken meat and tissues. Food Chem. 67, $27-31$.

Desai, M., Gayle, D., Babu, J. \& Ross, M.G., 2005. Programmed obesity in intrauterine growth-restricted newborns: Modulation by newborn nutrition. Am. J. Physiol. Regul. Integr. Comp. Physiol. 288, 91-96.

Desai, M., Gayle, D., Babu, J. \& Ross, M.G., 2007. The timing of nutrient restriction during rat pregnancy/lactation alters metabolic syndrome phenotype. Am. J. Obstet. Gynecol. 196, 1-7.

Dong, L., Zhong, X., Ahmad, H., Li, W., Wang, Y., Zhang, L. \& Wang, T., 2014. Intrauterine growth restriction impairs small intestinal mucosal immunity in neonatal piglets. J. Histochem. Cytochem. 62, 510-518.

Ferre, S., Veenstra, G.J., Bouwmeester, R., Hoenderop, J.G. \& Bindels, R.J., 2011. Hnf-1b specifically regulates the transcription of the gammaa-subunit of the Na+/K+-atpase. Biochem. Bioph. Res. Commun. 404, 284-290.

Gharibzahedi, S.M.T. \& Jafari, S.M., 2017. The importance of minerals in human nutrition: Bioavailability, food fortification, processing effects and nanoencapsulation. Trends Food Sci. Tech. 62, 119-132.

Gupta, M., Solanki, M.H., Chatterjee, P.K., Xue, X., Roman, A., Desai, N., Rochelson, B. \& Metz, C.N, 2014. Maternal magnesium deficiency in mice leads to maternal metabolic dysfunction and altered lipid metabolism with fetal growth restriction. Mol. Med. 20, 332-340.

He, J., Dong, L., Xu, W., Bai, K., Lu, C., Wu, Y., Huang, Q., Zhang, L. \& Wang, T., 2015. Dietary tributyrin supplementation attenuates insulin resistance and abnormal lipid metabolism in suckling piglets with intrauterine growth retardation. PLOS ONE 10, e0136848. 
Heidet, L., Decramer, S., Pawtowski, A., Moriniere, V., Bandin, F., Knebelmann, B., Lebre, A.S., Faguer, S., Guigonis, V., Antignac, C. \& Salomon, R., 2010. Spectrum of hnf1b mutations in a large cohort of patients who harbor renal diseases. Clin. J. Am. Soc. Nephro. 5, 1079-1090.

Kovacs, C.S., 2014. Bone development and mineral homeostasis in the fetus and neonate: Roles of the calciotropic and phosphotropic hormones. Physiol. Rev. 94, 1143-1218.

Kues, W.A. \& Niemann, H., 2004. The contribution of farm animals to human health. Trends Biotechnol. 22, $286-294$.

Li, B., Li, W., Ahmad,H ., Zhang, L., Wang, C. \& Wang, T., 2015. Effects of choline on meat quality and intramuscular fat in intrauterine growth retardation pigs. PloS. One. 10, e0129109.

Li, J., Funato, M., Tamai, H., Wada, H., Nishihara, M., Morita, T., Miller, S.L. \& Egashira, K., 2016. Impact of intra-and extrauterine growth on bone mineral density and content in the neonatal period of very-low-birth-weight infants. Early Hum. Dev. 92, 1-6.

Li, W., Li, B., Lv, J., Dong, L., Zhang, L. \& Wang, T., 2016. Choline supplementation improves the lipid metabolism of intrauterine-growth-restricted pigs. Asian-Austral. J. Anim. Sci. (Accepted).

Liu, K. \& Czaja, M.J., 2013. Regulation of lipid stores and metabolism by lipophagy. Cell. Death. Differentiat. 20, 3-11.

Livak, K.J. \& Schmittgen, T.D., 2001. Analysis of relative gene expression data using real-time quantitative pcr and the 2- $\triangle \Delta C T$ method. Methods. 25, 402-408.

Martin, K., Gabor, Z., Jozef, S., Julian, W. \& Monika, S., 2003. Mrs2p is an essential component of the major electrophoretic mg2+ influx system in mitochondria. Embo. J. 22, 1235-1244.

Mataloun, M. \& Leone, C., 2000. Human milk mineral intake and serum concentrations of calcium and phosphorus in newborn term infants: Influence of intrauterine growth restriction. Acta Paediatr. 89, 1093-1097.

Moltu, S.J., Strømmen, K., Blakstad, E.W., Almaas, A.N., Westerberg, A.C., Brække, K., Rønnestad, A., Nakstad, B., Berg, J.P. \& Veierød, M.B., 2013. Enhanced feeding in very-low-birth-weight infants may cause electrolyte disturbances and septicemia - a randomized, controlled trial. Clin. Nutr. 32, 207-212.

Pearce, A., Richards, R., Milz, S., Schneider, E. \& Pearce, S., 2007. Animal models for implant biomaterial research in bone: A review. Eur. Cell Mater. 13, 1-10.

NRC, 1998. Nutrient requirements of swine (10th ed.). National Academy Press, Washington, DC, USA.

Poore, K.R. \& Fowden, A.L., 2004. The effects of birth weight and postnatal growth patterns on fat depth and plasma leptin concentrations in juvenile and adult pigs. J. Physiol. 558, 295-304.

Prestridge, L.L., Schanler, R.J., Shulman, R.J., Burns, P.A. \& Laine, L.L., 1993. Effect of parenteral calcium and phosphorus therapy on mineral retention and bone mineral content in very low birth weight infants. J. Pediatr. 122, 761-768.

Raupp, P., von Kries, R., Schmiedlau, D. \& Manz, F., 1990. Biochemical evidence for the need of long-term mineral supplementation in an extremely low birth weight infant fed own mother's milk exclusively during the first 6 months of life. Eur. J. Pediatr. 149, 806-808.

Roman, A., Desai, N., Rochelson, B., Gupta, M., Solanki, M., Xue, X.Y., Chatterjee, P.K. \& Metz, C.N., 2013. Maternal magnesium supplementation reduces intrauterine growth restriction and suppresses inflammation in a rat model. Am. J. Obstet. Gynecol. 208, 1-7.

Roman, A., Gupta, M., Carreon, C., Nanda, N., Xue, X.Y., Williamson, A., Rochelson, B. \& Metz, C., 2015. Maternal magnesium supplementation reduces placental infarction and apoptosis in a rat model of intrauterine growth restriction. Am. J. Obstet. Gynecol. 212, 370.

Romani, A.M., 2011. Cellular magnesium homeostasis. Archi. Biochem. Biophy. 512, 1-23.

Schanler, R.J. \& Garza, C., 1988. Improved mineral balance in very low birth-weight infants fed fortified human milk. J. Pediatr. 112, 452-456.

Schanler, R.J., Garza, C. \& Smith, E.B., 1985. Fortified mothers' milk for very low birth weight infants: Results of macromineral balance studies. J. Pediatr. 107, 767-774.

Senterre, T. \& Rigo, J., 2011. Optimizing early nutritional support based on recent recommendations in VLBW infants and postnatal growth restriction. J. Pediatr. Gastr. Nutri. 53, 536-542.

Senterre, T. \& Rigo, J., 2012. Reduction in postnatal cumulative nutritional deficit and improvement of growth in extremely preterm infants. Acta Paediatr. 101, 64-70.

Singh, R., Kaushik, S., Wang, Y., Xiang, Y., Novak, I., Komatsu, M., Tanaka, K., Cuervo, A.M. \& Czaja, M.J., 2009a. Autophagy regulates lipid metabolism. Nature. 458, 1131-1135.

Singh, R., Xiang, Y., Wang, Y., Baikati, K., Cuervo, A.M., Luu, Y.K., Tang, Y., Pessin, J.E., Schwartz, G.J. \& Czaja, M.J., 2009b. Autophagy regulates adipose mass and differentiation in mice. J. Clin. Inves. 119, 3329-3339.

Sontia, B. \& Touyz,R.M., 2007. Magnesium transport in hypertension. Pathophysiology 14, 205-211.

Swaminathan, R., 2003. Magnesium metabolism and its disorders. Clin. Biochem. Rev. 24, 47-66.

Tsuyuki, S., Takabayashi,M., Kawazu,M., Kudo,K., Watanabe,A., Nagata,Y., Kusama,Y. \& Yoshida,K., 2014. Detection of wipi1 mrna as an indicator of autophagosome formation. Autophagy. 10, 497-513.

Van Angelen, A.A., San-Cristobal, P., Pulskens, W.P., Hoenderop, J.G. \& Bindels, R.J., 2013. The impact of dietary magnesium restriction on magnesiotropic and calciotropic genes. Nephrol. Dial. Transpl. 28, 2983-2993.

Vickers, M.H., 2014. Early life nutrition, epigenetics and programming of later life disease. Nutrients. 6, 2165-2178.

Wang, C., Lu, J., Zhou, L., Li, J., Xu, J., Li, W., Zhang, L., Zhong, X. \& Wang, T., 2016. Effects of long-term exposure to zinc oxide nanoparticles on development, zinc metabolism and biodistribution of minerals ( $\mathrm{Zn}, \mathrm{Fe}, \mathrm{Cu}, \mathrm{Mn})$ in mice. Plos. One. 11, e0164434.

Wu, G., Bazer, F.W., Wallace, J.M. \& Spencer, T.E., 2006. Board-invited review: Intrauterine growth retardation: Implications for the animal sciences. J. Anim. Sci. 84, 2316-2337.

Xu, R.J., Mellor, D.J., Birtles, M.J., Reynolds, G.W. \& Simpson, H.V., 1994. Impact of intrauterine growth retardation on 
the gastrointestinal tract and the pancreas in newborn pigs. J. Pediatr. Gastr. Nutri. 18, 231-240.

Zhang, H., Chen, Y., Li, Y., Yang, L., Wang, J. \& Wang, T., 2014. Medium-chain TAG attenuate hepatic oxidative damage in intra-uterine growth-retarded weanling piglets by improving the metabolic efficiency of the glutathione redox cycle. Brit. J. Nutri. 112, 876-885.

Zhang, H., Li, Y., Hou, X., Zhang, L. \& Wang, T., 2016. Medium-chain TAG improve energy metabolism and mitochondrial biogenesis in the liver of intra-uterine growth-retarded and normal-birth-weight weanling piglets. Brit. J. Nutri. 115, 1521-1530.

Zhang, H., Li, Y., Su, W., Ying, Z., Zhou, L., Zhang, L. \& Wang, T., 2017. Resveratrol attenuates mitochondrial dysfunction in the liver of intrauterine growth retarded suckling piglets by improving mitochondrial biogenesis and redox status. Mol. Nutri. Food Res. 61(5). doi: 10.1002/mnfr.201600653. 